\title{
Inverse Modelling of Climate Adaptive Building Shells. System Dynamics Approach
}

\author{
Toms $\operatorname{MOLS}^{1 *}$, Andra BLUMBERGA ${ }^{2}$ \\ ${ }^{1,2}$ Institute of Energy Systems and Environment, Riga Technical University, Azenes iela 12/1, \\ Riga, LV-1048, Latvia
}

\begin{abstract}
The paper describes the development of a computer-based inverse model for climate adaptive building shell which is in the cold climatic conditions of Latvia to determine changes in energy consumption. Types, principles of operation and classification of climate adaptive building shells (CABS) were reviewed and CABS most fitting to Latvia's climate conditions were chosen for application in the model. Research implies that building modelling tools play an important role in the design phase. The results indicate that hourly facade adjustment can have a significant impact on GHG emissions and energy consumption reduction without compromising the comfort level. Optimization is proven to be an essential part of the inverse modelling phase, which provides the best possible option defined by the user for the characteristics that distinguish climate adaptive building shells. Inverse modelling approach allowed to determine necessary building enclosure parameters that need to be met to provide best performance.
\end{abstract}

Keywords - Climate adaptive building shells; energy efficiency; inverse modelling; optimization; system dynamics

\section{INTRODUCTION}

Energy efficiency is one of the most important aspects that could support decreasing the total consumption of energy. It is anticipated that by 2040 total energy consumption will have increased by $48 \%$. In order to minimize the increase of energy demand, it is essential to develop new and upgrade existing infrastructure systems in every economic sector [1]-[3].

Climate-adaptive building shell (CABS) is a term in building engineering that describes the group of facades and roofs that interact with the variability in their environment in a dynamic way. CABS are expected to play a significant role in the building sector. Currently the development of the concept has a wide range for improvement. This concept has been known in the field of research for more than thirty years but has received special attention only in the last decade. CABS offer the opportunity to improve energy efficiency in buildings, indoor microclimate and maximize the use of "free" energy that is available, which has a positive effect on the overall energy balance. Given the latest advancements in material development, as well as the development of various sensors and controls, such a shift to adaptive structures should practically not produce any technological barriers, however, as the current situation shows, the innovative and unique use of CABS in buildings is relatively rare. Various CABS descriptions are available in scientific literature, most of which are at the research stage or are developed at the laboratory level. Comparatively fewer are those real examples, developed at the market level, and most of

* Corresponding author.

E-mail address: mols.toms@gmail.com 
them, for which information is available, are created as individual architectural solutions that have both practical and high aesthetic value [4], [5].

The concept of CABS may play a significant role in decreasing energy demand in a building without negatively affecting indoor comfort levels and contemporary lifestyle standards. Additionally, CABS promote use of renewable resources thus replacing fossil fuel correspondingly decreasing GHG emissions [6].

\section{SYSTEM MODELLING SOFTWARE. REQUIREMENTS AND RESTRICTIONS}

About one third of the building's energy consumption is used to increase thermal comfort and illumination. Now even the initial building at the design stage requires tools that can provide answers to specific questions. Using building modelling tools, building designers can consider various potential scenarios, such as heating and cooling, as well as choosing the best refurbishment solutions in existing buildings, assessing the energy balance of the building and energy costs. In addition to energy consumption indicators, variables such as indoor temperature, heating and cooling, natural light, ventilation, etc. can be calculated by modelling tools [7], [16].

A large part of building modelling tools has evolved gradually, providing the user with ever new opportunities. The modelling and simulation of adaptive buildings should show how the structure of the building or the specific parameters of the building change. At the time when building modelling software was designed, it was not designed for modelling of adaptive building designs, therefore, most of the available modelling tools lack a wide range of possibilities for determining the CABS performance, since the construction parameters in these tools are defined as constants and remain constant throughout the simulation, therefore, applied and sought simplified simulation approaches. A few of the most commonly used modelling software tools are [8], [9], [17], [18]:

- Energy plus;

- TRNSYS;

- ESP-r.

\section{Requirements and restrictions for existing building modelling tools.}

From all of the modelling tools discussed, EnergyPlus has been powered by the most comprehensive CABS modelling and simulation capabilities since its inception, gradually evolving and developing to meet today's needs. It is important to mention that this is a free, open source software tool that makes it more attractive to the user than for instance TRNSYS software tool. There is wide potential for development and improvement with regard to the possibilities of modelling software tools, which in the future will provide wider possibilities for CABS modelling and simulation [10], [11].

CABS simulation involves high level interphase interactions and information exchange between other energy systems in the building, so it is important for users to develop appropriate simulation strategies by matching the CABS performance objectives with the capabilities and limiting factors of different modelling tools. In general, considering the possibilities of building modelling tools for $\mathrm{CABS}$, it can be said that they are relatively early in their development stages and there are many other aspects that require further research in this field.

Simulation and simulation using Powersim Studio, the leading system simulator for system dynamics, is based on system dynamics, a computer-based modelling technique developed in Massachusetts Institute of Technology in 1950 as a system for analysing complex systems. The 
programmer is widely used in the academic environment to model various economic, biological and physical systems [19].

The structure of any system, no matter how simple or complex it is, can be modelled using variables and their connections, hence also buildings and CABS. As the main elements used to create a model, there are stocks, flows, boundary flows, auxiliaries, constants, interconnection information between elements (delay link, initial value link), which are defined by mathematical equations (see Fig. 1) [19], [20].

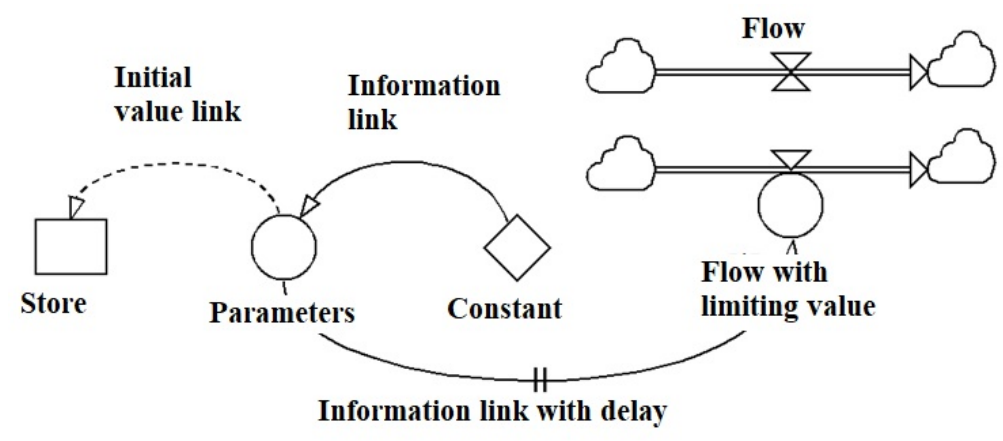

Fig. 1. Main elements that are used to build a model with Powersim Studio.

The stock describes the accumulation of values and the decrease in value through incoming and outgoing flows. The parameters are used to merge and / or reformulate the information. Constants define constant values for all simulations. Information links link resources, ancillaries and constants to each other, and show how individual elements of the model are interconnected [20].

\section{INVERSE MODELLING}

Building modelling approaches can be divided into two categories: 1) classical (direct) modelling and 2) reverse (inverse) or data-driven modelling. Direct modelling as input data takes physical measurements of the building, which may include the location of the building, local weather, geometry, construction materials, operating schedule, type of heating ventilation and air conditioning system, etc. Direct modelling is usually used in the design phase of buildings. The inverted model uses data from the building's energy consumption data, expressed as one or more variables and an empirical set of parameters, as input data. The input data is used to find the parameters that provide the best fit for the selected model and data set [12], [26].

The energy balance in Bart de Boer et al. [18] study is expressed as an equation of three variables: U value, air exchange rate and solar heat gain coefficient, therefore one unique solution cannot be found. When modelling the minimum hourly energy balance value (energy balance is generally expressed as the difference between heat gain (from the sun and humans) and heat loss (through the facade and ventilation)), maximizing the use of solar energy is prioritized by reducing heat loss through the facade and ventilation - when such a solution generates excess heat, the benefits of solar heat are first reduced, and only then the heat transfer and ventilation are increased [21], [22]. 
Most of the available modelling tools lack extensive capabilities to measure the CABS's performance, so researchers are always looking for ways to make better use of existing tools or develop new tools that are not widely available.

Inverse modelling is closely related to optimization. When dealing with climate adaptive building shells it is essential to choose the right values among many systems.

\section{OPTIMIZATION SOFTWARE}

The words "optimum" and "optimus" from Latin mean the best, which also characterizes the essence of optimization - to find the best possible situation, the best solution for any system. Optimization is used to solve mathematical problems that arise during real process simulation [22], [23].

TABLE 1. Customized AND General Optimization TOOLS [10]

\begin{tabular}{|c|c|c|c|c|c|c|}
\hline \multicolumn{2}{|c|}{ Optimization tools } & \multirow{2}{*}{$\begin{array}{l}\text { Q1 } \\
\text { Yes }\end{array}$} & \multirow{2}{*}{$\begin{array}{l}\text { Q2 } \\
\text { No }\end{array}$} & \multirow{2}{*}{$\begin{array}{l}\text { Q3 } \\
\text { No }\end{array}$} & \multirow{2}{*}{$\begin{array}{l}\text { Q4 } \\
\text { No }\end{array}$} & \multirow{2}{*}{$\begin{array}{l}\text { Q5 } \\
\text { No }\end{array}$} \\
\hline \multirow{6}{*}{ 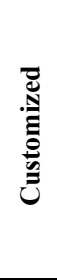 } & Opt-E-Plus & & & & & \\
\hline & $G E N E \_A R C H$ & Yes & Yes & No & No & No \\
\hline & BEopt $t^{\mathrm{TM}}$ & Yes & No & No & No & No \\
\hline & TRNOPT & No & Yes & No & No & Yes \\
\hline & MultiOpt2 & No & Yes & Yes & Not enough info & Yes \\
\hline & $j E P l u s+E A$ & No & Yes & No & Yes & No \\
\hline \multirow{6}{*}{ 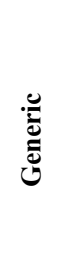 } & GenOpt & Yes & No & No & Yes & Yes \\
\hline & Model-Center & No & Yes & Partly & Yes & No \\
\hline & modeFRONTIER & No & Yes & Yes & Yes & Yes \\
\hline & DAKOTA & Yes & Yes & Yes & Yes & Yes \\
\hline & $i S I G H T$ & No & Yes & Yes & No & Yes \\
\hline & MATLAB Optimization toolboxes & No & Yes & Partly & Yes & No \\
\hline
\end{tabular}

-Q1: Is it a freeware?

- Q2: Does it include multi-objective algorithms?

-Q3: Does it handle constraint functions automatically?

- Q4: Does it allow parallel computing?

- Q5: Can it handle discrete and continuous variables simultaneously?

*Yes/No means that the answer is 'yes' for some algorithms and 'no' for other algorithms in the reviewed optimization tool.

Even though many different optimization tools are available that provide a variety of features, the desire to create new optimization tools still exists. The need for a universal optimization tool, which is free, can be integrated with other modelling tools and eliminates the gaps in existing optimization tools, serves as the main motivation factor for Academy of Finland funded optimization tool Mobo (Multi-Objective Building Optimization) creation [24].

When optimizing the building, among the very large number of possible combinations, it is possible to find the optimal values of the variables that simultaneously fit within the specified boundary functions and satisfy the target functions. Examples of optimization targets in buildings can include environmental aspects (energy consumption, emission reductions, energy efficiency), 
costs, comfort level, etc. Optimal solutions can be sought for each case individually and simultaneously by multi-objective optimization [13]-[15], [24].

\section{System Dynamics Model for Climate Adaptive Building Shells}

The model is created for a general case without dividing a particular climate adaptive building shell. The function, which is based on all active window technologies, is the ability to change the solar heat gain coefficient ( $g$ value). The model determines that the solar heat gain coefficient can vary within certain limits, but the way this change occurs (external, internal blinds, reflective light elements, etc.) is not reflected in the model.

The energy consumption of a building can be calculated by determining the heat output and heat loss of the building, which forms the energy balance of the building. Such a process is the basis for any energy audit of the building. As a basis for the active window model built in the Powersim Studio environment, the renovation of the building described in the manual on sustainable building design and engineering is used: in this case, all the necessary parameters characterizing the building are made available, which facilitates the creation of the model [25].

The adaptation of the model to climatic conditions is provided using real climate data: in this case the ambient air temperature $\left({ }^{\circ} \mathrm{C}\right.$, hourly values per year), as well as solar radiation data $\left(\mathrm{W} / \mathrm{m}^{2}\right.$, hourly global solar radiation values per year) are applied. Considering the availability of free access to climate data available at an hour or less, the model uses the climate files available in the TRNSYS demo version that can be exported to the Excel environment and further imported into the Powersim Studio environment using model simulations. The model selected the closest and most relevant data file for the Latvian climate available in the TRNSYS demo version: Russia, Moscow.

During the simulation, the energy consumption required for a particular building from the current outdoor temperature and solar radiation is determined and the heat losses through the windows are determined separately. Initially, a simulation of the model is performed in cases where the CABS is not used in the building - an active window with external insulation providing a constant heat transfer coefficient. During this simulation period, this coefficient is constant and equals the $U$ value of the window $1.5 \mathrm{~W} / \mathrm{m}^{2} \mathrm{~K}$ ). In order to determine the energy consumption and heat loss through window construction, if a CABS is used in the building, simulation of the model is made, which defines that at the time when the radiation of the sun is equal to 0 , insulating, window-covering panels are used which, during the hours when there is no sun radiation, provides smaller $U$ value by half, or $0.6 \mathrm{~W} / \mathrm{m}^{2} \mathrm{~K}$.

To determine most suitable solar heat gain coefficient, model optimization in Powersim Studio environment was made. For each hour a corresponding heat gain coefficient value was calculated so that energy balance would be equal to zero. This was defined as a constraint. In the model energy balance had been defined as objective function whereas solar heat gain coefficient is variable ranging from 0.06 to 0.85 . 


\section{RESULTS}

After the model simulation, the result obtained is shown in Fig. 2 with a green line. When comparing energy consumption data with outdoor air temperature values, it is apparent that the simulation data obtained are in line with the expected scenario - the colder the outdoor air temperature, the higher the energy consumption. A purple line shows the result obtained after optimization.

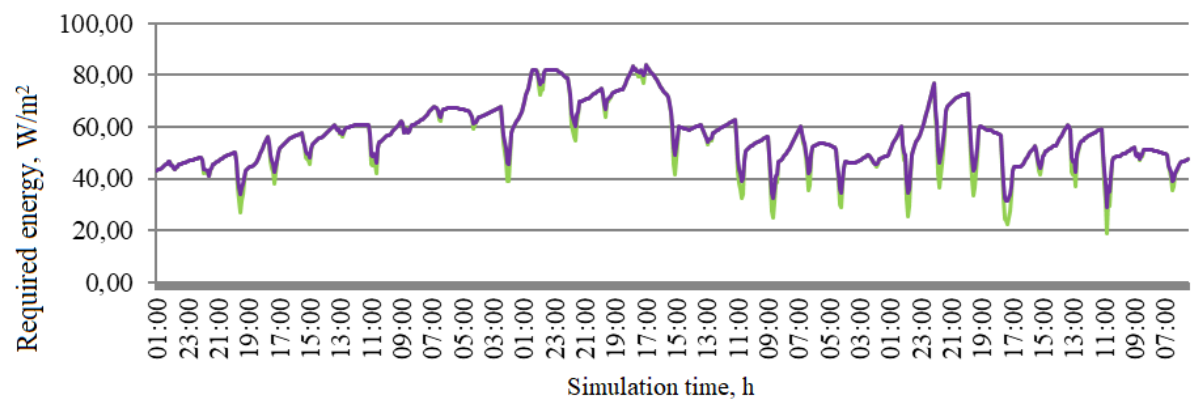

- Required thermal energy for a building without CABS at constant solar thermal input

- Required thermal energy for a building with $\mathrm{CABS}$ at a variable solar thermal input

Fig. 2. Required energy with and without CABS in January month.

After Fig. 2, it is shown that the use of CABS, which adapts to the solar radiation level during the winter, would yield minimal benefits, due to relatively low solar radiation values. Proposals for a percentage gain result in a potential reduction in thermal energy of just over $1 \%$.

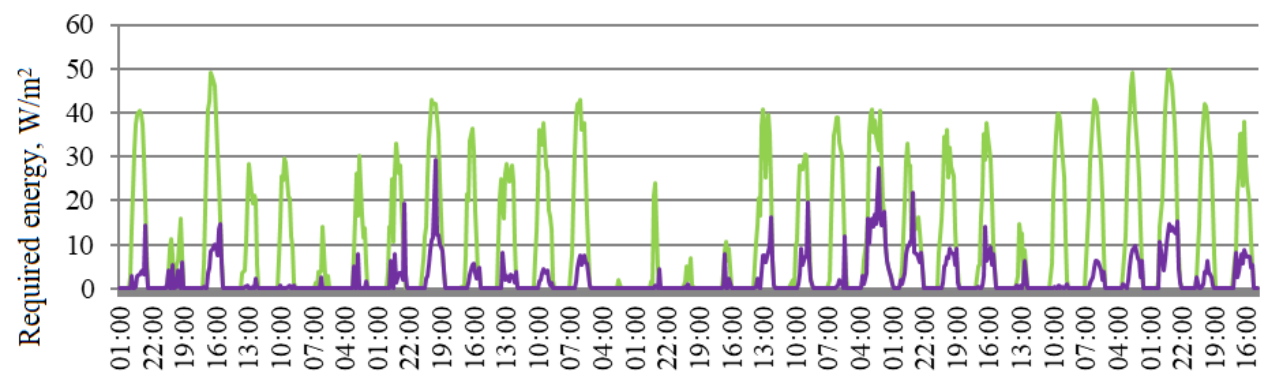

Simulation time, $\mathrm{h}$

— Required thermal energy for a building without CABS at constant solar thermal input

— Required thermal energy for a building with $\mathrm{CABS}$ at a variable solar thermal input

Fig. 3. Required energy with and without CABS in July month.

Fig. 3 shows difference between required energy with and without the application of CABS in July month. It was calculated that with a static construction in July month $7.2 \mathrm{kWh} / \mathrm{m}^{2}$ power for cooling was necessary. With the application of CABS, this demand can be decreased by approximately $80 \%$ or down to $1.5 \mathrm{kWh} / \mathrm{m}^{2}$. 
Comparing the results obtained between January and July, it is clear that the technology in question has the greatest benefits in terms of cooling capacity reduction. Similar findings are also mentioned in the publications by F. Favoino et al. [21] and A. Taal \& L. Itard [25]. During the summer, simulations show a minimal amount of solar gain, but in the winter, on the contrary, the adaptive design tries to maximize the benefits of solar heat, but the potential for energy savings is minimal. In the winter months, when the solar radiation is low, buildings in the cold climate zone need to look for another, more suitable CABS solution [26], [27].

Reviewed energy performance results of buildings where climate adaptive building shells are applied is based on hourly adaptation to changing conditions. Inverse modelling approach allows to determine necessary building enclosure parameters that need to be met to provide best performance. In further research it would be beneficial to inspect cases where seasonal adaptiveness of building facades could be enough for improvement of energy balance and overall performance.

\section{CONCLUSIONS}

CABS have great potential for reducing GHG emissions and energy consumption in buildings, while ensuring and not affecting the desired indoor climate from the user's point of view. The concept of CABS has been known for over 30 years but has just begun to receive special attention in the last decade, looking for ways to increase the energy efficiency of buildings. Although the scientific literature describes countless existing and new CABS case studies, the CABS concept cannot be considered "mature". Their further development is related not only to overcoming technological but also economic, legal and social barriers.

Modelling tools for buildings play an important role in the construction design phase of the initial building to look for specific questions and consider different potential scenarios for heating, cooling or renovation approaches when assessing the energy balance of the building and the cost of energy before the project is implemented. The most well-known tools for modelling building performance are subject to a number of constraints that preclude the precise prediction of CABS's performance and benefits, therefore there is a demand for new and effective software tools, as well as creative and innovative approaches are being sought on how to make the most efficient use of available software tools to get as accurate as possible building models that include CABS. The performance of several CABS with currently available model-specific simulation models cannot be estimated, but general-use models, even more flexible, require a knowledge base at an expert level. Powersim Studio, which integrates the optimization module, is an appropriate modelling tool to determine or predict the performance of CABS. Powersim Studio, in comparison with other modelling tools, makes it easy to create a building model that changes the value of the parameters during simulation.

Optimization is an essential part of the inverse modelling phase, which provides the best possible option defined by the user for the characteristics that characterize CABS, which has an impact on energy performance and indoor comfort in buildings.

However, in this study facade design was reviewed from energy performance perspective. The designers must find compromise between solar heat gain, daylight access and view from inhabitant's perspective. 


\section{ACKNOWLEDGEMENT}

The research is funded by the Ministry of Economics of the Republic of Latvia, project "Improvement of building energy efficiency technologies (I-BEET)" project No. VPP-EM-EE-2018/1-0003.

\section{REFERENCES}

[1] U.S. Energy Information Administration (EIA). EIA projects 48\% increase in world energy consumption by 2040 . In Today in Energy. [Online]. [Accessed 12.03.2020]. Available: https://www.eia.gov/todayinenergy/detail.php?id=26212

[2] European Commission. Energy efficient buildings [Online]. [Accessed 11.04.2020]. Available: https://ec.europa.eu/energy/en/topics/energy-efficiency/buildings

[3] Loonen R. C. G. M. Climate Adaptive Building Shells What can we simulate? Master Sci. Thesis. 2009:3:6-11.

[4] Wang T., et al. GHG emission reduction performance of state-of-the-art green buildings: Review of two case studies. Renewable and Sustainable Energy Reviews 2016:56:484 493. https://doi.org/10.1016/j.rser.2015.11.037

[5] Bodach S., Lang W., Hamhaber J. Climate responsive building design strategies of vernacular architecture in Nepal. Energy and Buildings 2014:81:227-242. https://doi.org/10.1016/j.enbuild.2014.06.022

[6] Laicane I., et al. Evaluation of Household Electricity Savings. Analysis of Household Electricity Demand Profile and User Activities. Energy Procedia 2015:72:285-292. https://doi.org/10.1016/j.egypro.2015.06.041

[7] Sousa J. Energy Simulation Software for Buildings: Review and Comparison. Computer Science 2012:6-7.

[8] ESP-r. ESP-r, Multi-platform Building Energy Software Tool [Online]. [Accessed 22.04.2017]. Available: http://www.esru.strath.ac.uk/Programs/ESP-r_overview.htm

[9] Loonen R. C. G. M., et al. Review of current status, requirements and opportunities for building performance simulation of adaptive facades. Journal of Building Performance Simulation 2016:10(2):203-223. https://doi.org/10.1080/19401493.2016.1152303

[10] Loonen R. G. C. M., et al. Performance Simulation of Climate Adaptive Building Shells: Smart Energy Glass as a case study. Presented at the 8th International Conference on System Simulation in Buildings, Liege, Belgium, 2010.

[11] Harish V. S. K. V., Kumar A. A review on modeling and simulation of building energy systems. Renewble and Sustainable Energy Reviews 2016:56:1272-1292. https://doi.org/10.1016/j.rser.2015.12.040

[12] Loonen R. C. G. M., et al. Simulation-based support for product development of innovative building envelope components. Automation in Construction 2014:45:86-95. https://doi.org/10.1016/j.autcon.2014.05.008

[13] Blumberga A. Integrating systemic thinking into environmental policy. Riga: Riga Technical University, 2010. (in Latvian)

[14] Powersim Studio 8 Academic (8.10.4916.6). Powersim Studio 8 Help. Building Blocks in Powersim Studio.

[15] Kramer R., van Schijndel J., Schellen H. Inverse modeling of simplified hygrothermal building models to predict and characterize indoor climates. Building and Environment 2013:68:87-99. https://doi.org/10.1016/j.buildenv.2013.06.001

[16] Favoino F., Overend M., Jin Q. The optimal thermo-optical properties and energy saving potential of adaptive glazing technologies. Applied Energy 2015:156:1-15. https://doi.org/10.1016/j.apenergy.2015.05.065

[17] Andréasson N., Evgrafov A., Patriksson M. An Introduction to Optimization: Foundations and Fundamental Algorithms. 2005.

[18] De Boer B., et al. Climate Adaptive Building Shells for the future-Optimization with an Inverse Modelling Approach. Proceedings of the ICEEE Summer Study 2011 2011:1413-1422.

[19] Kova A. Using Metamodeling for the Analysis and Optimization of Dynamic Systems. Riga: RTU, 2012. (in Latvian)

[20] Palonen M., Hamdy M., Hasan A. Mobo a new software for multi-objective building performance optimization. Proceedings of the Building Simulation 2013 - 13th International IBPSA Conference 2013:2567-2574.

[21] Favoino F., Overend M. A simulation framework for the evaluation of next generation Responsive Building Envelope technologies. Energy Procedia 2015:78:2602-2607. https://doi.org/10.1016/j.egypro.2015.11.302

[22] Stephan L., Bastide A., Wurtz E. Optimizing opening dimensions for naturally ventilated buildings. Applied Energy 2011:88(8):2791-2801. https://doi.org/10.1016/j.apenergy.2010.12.039

[23] Kasinalis C., et al. Framework for assessing the performance potential of seasonally adaptable facades using multiobjective optimization. Energy in Buildings 2014:79:106-113. https://doi.org/10.1016/j.enbuild.2014.04.045

[24] Mumovic D., Santamouris M. A Handbook of Sustainable Building Design and Engineering: An Integrated Approach to Energy, Health and Operational Performance. International Journal of Sustainability in Higher Education 2009:10(4):474.

[25] Taal A., Itard L. Shell Optimization of a Climate Adaptive Greenhouse Using Inverse Modeling. Proceedings of the Building Simulation 2013 - 13th International IBPSA Conference 2013:2250-2255. 